RESEARCH REPORT

\title{
Impact of smoking on the social gradient in health expectancy in Denmark
}

\author{
Henrik Brønnum-Hansen, Knud Juel
}

J Epidemiol Community Health 2004;58:604-610. doi: 10.1136/jech.2003.012955

See end of article for authors' affiliations

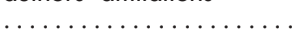

Correspondence to: Mr H Brønnum-Hansen, National Institute of Public Health, 25 Svanemøllevej, DK 2100 Copenhagen $\varnothing$, Denmark; hbh@niph.dk

Accepted for publication 14 September 2003

\begin{abstract}
Study objective: Health expectancy is arrived at by dividing life expectancy into average lifetime in different states of health. The purpose of the study was to estimate health expectancy among never smokers and smokers in groups at high, medium, and low educational levels in Denmark.

Design: Life tables for never smokers and smokers with a high, medium, and low educational level were constructed on the basis of Statistics Denmark registers and combined with data from the Danish Health Interview Survey 2000. Health expectancy was calculated by Sullivan's method.

Main results: Life expectancy at age 30 differs on average by 8.5 years between never smokers and heavy smokers. Expected lifetime in self rated good health was 39.4 years for a never smoking man corresponding to $82.0 \%$ of the rest of his life. For male lifelong heavy smokers these figures were reduced to 27.3 years and $69.2 \%$. The proportion of expected lifetime in self rated good health was $89.5 \%$ and $71.3 \%$ among male never smokers and lifelong heavy smokers with a high educational level, respectively; and the proportion among male never smokers and heavy smokers with a low educational level was $73.4 \%$ and $63.6 \%$, respectively. Similar results were seen as regards expected lifetime without longstanding illness. For women the social gradient in health expectancy was intensified among smokers. Conclusions: Within each educational group smoking reduces expected lifetime in a healthy state. The social gradient in health expectancy cannot be explained by a reverse social gradient in smoking prevalence.
\end{abstract}

S ocial status and health are strongly related and smoking is more prevalent in lower than in higher social classes. Therefore, smoking is assumed to contribute to social inequality in health and studies estimating the relation between smoking and health may be confounded by the effect of social position. Several studies have attempted to quantify or compare the effect of smoking on mortality in different social classes. The interaction between social status, smoking, and health is not confined to mortality but also influences other measures of health outcome.

In Denmark life expectancy of a 20 year old never smoker is about seven years longer than that of a lifelong heavy smoker $(\geqslant 15$ g tobacco per day) and expected lifetime in self rated good health differs by 12 years. ${ }^{1}$ Life expectancy at age 30 in Danish men with high, medium, and low educational levels is $47.8,45.5$, and 43.5 years, respectively, and expected lifetime in self rated good health is $39.3,34.7$, and 29.5 years among men with high, medium, and low educational levels, respectively. ${ }^{2}$ For 30 year old Danish women life expectancy at the three educational levels is 51.3, 50.4, and 48.6 years, respectively and expected lifetime in self rated good health is 41.3 years at the high and 30.4 years at the low educational level. ${ }^{2}$ Smoking is more frequent among people at a low educational level than among people with higher education. Thus, in Denmark in 2000 the percentage of daily smoking among persons with a maximum of 10 years of schooling was about 40 , whereas the percentage among persons with 15 or more years of education was $22 .^{3}$ The proportion of heavy smokers was $22 \%$ among persons with a maximum of 10 years of schooling and $10 \%$ for people with at least 15 years of education.

The purpose of this study was to estimate health expectancy among never smokers and smokers in groups at high, medium, and low educational levels in Denmark and to investigate the impact of smoking on the social gradient in health expectancy.

\section{METHODS}

The simple and commonly used method for health expectancy calculation proposed by Sullivan requires life tables and data on the prevalence of health status. ${ }^{4}$ To estimate health expectancy in population groups at different educational levels and smoking categories we need life tables and health status data for each combination of these groups. On the basis of a unique personal identification code assigned to all Danish citizens, life tables for the period 1996-2000 were constructed for three educational groups by linking national registers at Statistics Denmark on vital status and education. To estimate deaths caused by smoking data on the sex and age specific number of persons at risk and number of deaths of various causes during the period 1994-1998 for each educational group were extracted from Statistics Denmark registers. As data on education are not available for people over 75, the death rates for all educational groups were assumed to be the same after that age.

We defined three levels of education: low-persons with a maximum of 10 years of schooling and no more than semiskilled training, basic vocational training or business school (first year); medium-persons with either a maximum of 10 years of schooling and further vocational or other training or with post-secondary schooling but no higher education; and high-persons with any type of higher education. Life expectancy and health expectancy were estimated for 30 year olds on the assumption that most people have finished their education by that age.

\section{Estimating life tables by smoking category and educational level}

By the method suggested by Peto et al, we calculated for each educational group the proportion of smoking attributable deaths from lung cancer in 1994-1998 from the rates of death from lung cancer in Denmark and the rates for never smokers and smokers estimated from the second prospective cancer 
prevention study (CPS-II) of the American Cancer Society on smoking and mortality. By the formula $\mathrm{P}=(\mathrm{L}-\mathrm{A}) /(\mathrm{C}-\mathrm{A}) \mathrm{a}$ sex and age specific "synthetic smoking prevalence", $\mathrm{P}$, was estimated, L being the educational level specific Danish lung cancer death rate and $\mathrm{A}$ and $\mathrm{C}$ the lung cancer death rates among never smokers and smokers, respectively, according to the CPS-II. The "synthetic smoking prevalence" is the prevalence that would result in the observed rate of death from lung cancer in the population. In contrast with point prevalence the "synthetic smoking prevalence" summarises the history of smoking in the population so that the long term effect of smoking on health is taken into account. Indirectly it includes the influence of the proportion of smokers, the quantity smoked, the duration of smoking, the age when starting to smoke, and the prevalence of inhaling. On the basis of the "synthetic smoking prevalence" and relative risks taken from the CPS-II, we calculated the aetiological fractions for other smoking related causes of death: upper aerodigestive cancers, other cancers, chronic obstructive lung disease, other diseases of the respiratory system, vascular diseases, and other natural causes. However, to control for confounding and ensure that the hazards of tobacco were not exaggerated the aetiological fraction $\mathrm{P}(\mathrm{RR}-1) /(1+\mathrm{P}(\mathrm{RR}-1))$ was replaced by $\mathrm{P}(\mathrm{RR}-1) /$ $(2+\mathrm{P}(\mathrm{RR}-1))$, according to the method of Peto et al. Thus, deaths caused by smoking and deaths not caused by smoking were calculated. In particular, life tables for never smoking men and women in each educational group were estimated.

The Danish national cohort study (DANCOS), ${ }^{6}$ established by linking data from the Danish health interview survey for 1987, 1991, and 1994 with the Cause of Death Register and other national registers made it possible to estimate relative risks for death for ex-smokers, moderate smokers, and heavy smokers compared with never smokers. Relative risk estimates adjusted for sex and age were 1.2 for ex-smokers, 1.5 for moderate smokers, and 2.6 for heavy smokers. Relative risks were assumed to be independent of educational level and for each educational group, sex, and age specific death rates for never smokers were multiplied by the relative risk estimates giving sex and age specific death rates for each smoking category. However, because of the long delay before smoker's risk for death is increased, the relative risks (RRs) for people under 45 were reduced to $(R R+1) / 2$. Finally, life tables by educational group and smoking category were constructed. The method is described in greater detail in the appendix.

\section{The Danish health interview survey 2000}

For the Danish health interview survey 2000 a sample of 22486 people aged 16 or more was drawn from the Danish Civil Registration System. To eliminate seasonal variation, the interviews were conducted in three rounds, in February, May, and September 2000, the samples comprising 6557, 6797, and 9132 people, respectively. Carefully trained professionals from the Danish National Institute of Social Research interviewed 16690 persons (74.2\% of the sample). Details and results of the survey have been reported recently. $^{3}{ }^{7}$

Self rated health was measured by answers to the question: "How do you rate your present state of health in general?" The five original response categories (really good, good, fair, poor, and very poor) were dichotomised into "good" and "fair or poor". Longstanding illness was measured by answers to the question "Do you suffer from any longstanding illness, longstanding after effect of injury, any disability, or other longstanding condition?" Questions about schooling, vocational training, and further education were also asked.
The interviewees were categorised as never smokers, exsmokers, moderate smokers ( $1-14 \mathrm{~g}$ of tobacco per day), and heavy smokers ( $\geqslant 15 \mathrm{~g}$ of tobacco per day) according to answers to the question "Do you smoke?", with the answer categories "yes, daily", "yes, but some days I don't smoke", and "no" and questions as to the quantity of tobacco smoked. The question: "Have you ever been a smoker?" was asked to identify ex-smokers.

\section{Estimating health expectancy}

Health expectancy per educational level and smoking category was calculated by Sullivan's method, ${ }^{4}$ combining life table figures and prevalence data of health status. The expected number of years lived in the age intervals 30-34, $35-39, \ldots, 70-74, \geqslant 75$ were multiplied by age specific proportions of healthy people taken from the health survey data. Health expectancy for 30 year olds was calculated by adding these years for all age groups and dividing the sum by the number of survivors at age 30 . By relating health expectancy to life expectancy, a measure of the proportion of lifetime in good health was established. Confidence intervals were calculated from the formulas suggested by the International Network on Health Expectancy. ${ }^{8}$

\section{RESULTS}

\section{Life expectancy}

Life expectancy of a 30 year old man who will never start smoking was 48.1 years and 8.6 years longer than that of a lifelong heavy smoker (table 1). The difference between never smokers and moderate smokers was 3.7 years. Similar differences were seen for women. The difference in life expectancy between smoking categories was inversely related to educational level despite the fact that a person with a high educational level on average lives longer than a person with a low educational level. Thus, the difference in life expectancy between never smokers and heavy smokers was 7.5 years and 8.1 years for men and women with a high educational level, respectively, 8.5 years and 8.3 years for men and women with a medium educational level, and 8.9 years and 8.7 years for men and women with a low educational level. Another result deduced from table 1 is that the difference between 30 year old male never smokers with a high and a low educational level was 2.3 years, whereas the similar difference between educational levels among male lifelong heavy smokers was 3.7 years. The educational disparities for women were 1.3 years for never smokers and 1.9 years for heavy smokers.

\section{Expected lifetime in self rated good health}

The expected lifetime of a 30 year old man with a high educational level who will never start smoking was 49.2 years, 44.0 of which were expected to be in self rated good health. The corresponding figures for a male lifelong heavy smoker with a high educational level were 41.7 years, 29.8 of which were in self rated good health (table 1). A 30 year old never smoking man with a low educational level could expect to live a further 46.9 years, with 34.4 years in self rated good health, while life expectancy of a male heavy smoker with a low educational level was reduced to 38.0 years, 24.2 of which were expected to be spent in self rated good health. The corresponding results for ex-smokers and moderate smokers lie between those of never smokers and heavy smokers. The proportion of expected lifetime in self rated good health was lower for women than for men. Among men the social gradient was steeper for never smokers than for moderate smokers, ex-smokers, and heavy smokers, whereas, among women it was steepest for smokers. Figure 1 summarises the results shown in table 1 . 


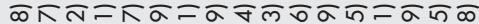

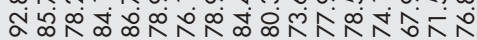
응ㅇㅇㅇㅇㅇㅇㅇㅇㅇㅇㅇㅇㅇㅇㅇㅇㅇㅇㅇㅇㅇㅇㅇㅇㅇㅇㅇㅇㅇㅇㅇㅇㅇ으으의 NN $0 \infty-0 \wedge m \nabla-0 \infty-\infty \nabla \infty N$

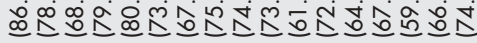

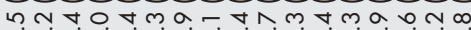

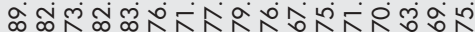

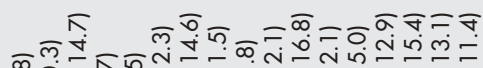

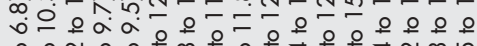

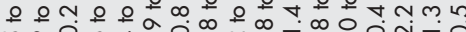

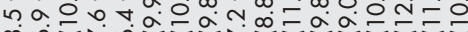
m는

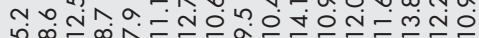

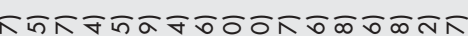

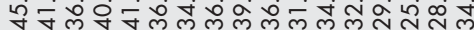
오오오오오오오옹ㅇㅇㅇㅇㅇㅇㅇㅇㅇㅇㅇㅇㅇㅇㅇㅇㅡ ব- तm च व ปै 0 o

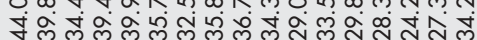

n $4 a-a \infty n+n \infty-\forall n a O n$

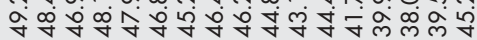

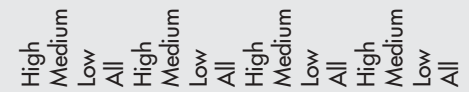

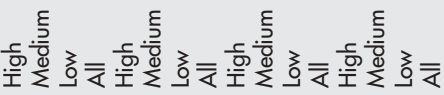

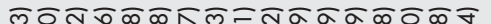

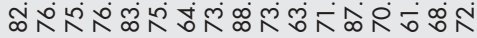
오으으으으으응ㅇㅇㅇㅇㅇㅇㅇㅇㅇㅇㅇㅇㅇㅇㅇㅇㅇㅇㅇㅇㅇㅇㅇㅇㅇ on

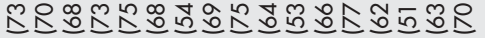
ho o o onhn na.

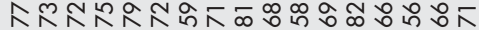

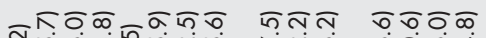

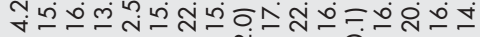
으으옹ㅇㅇㅇㅇㅇㅇ엉ㅇㅇㅇㅇㅇㅇㅇㅇㅇㅇㅇㅇㅇㅡ

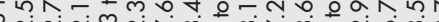

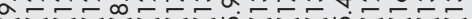

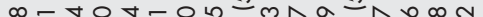

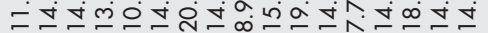

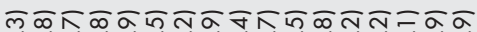

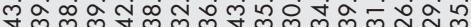
오오오오으으오으오오오으으오오오오

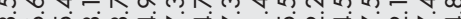
ळ్లో ר-

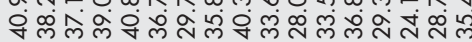

人 $\forall a-\infty \infty m \sim \infty \infty \nabla 0-\lambda \backsim \infty$ तु่ 
30 year old men

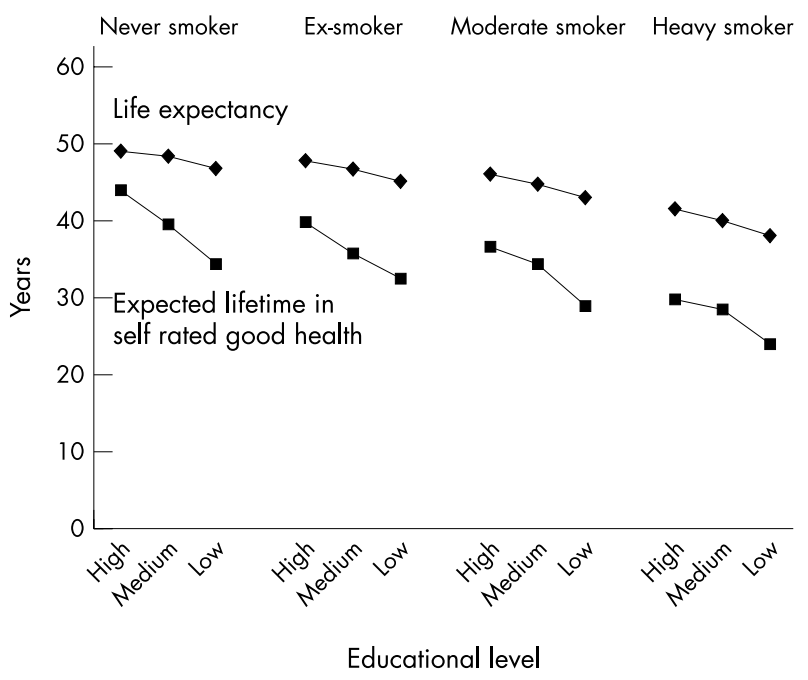

30 year old women

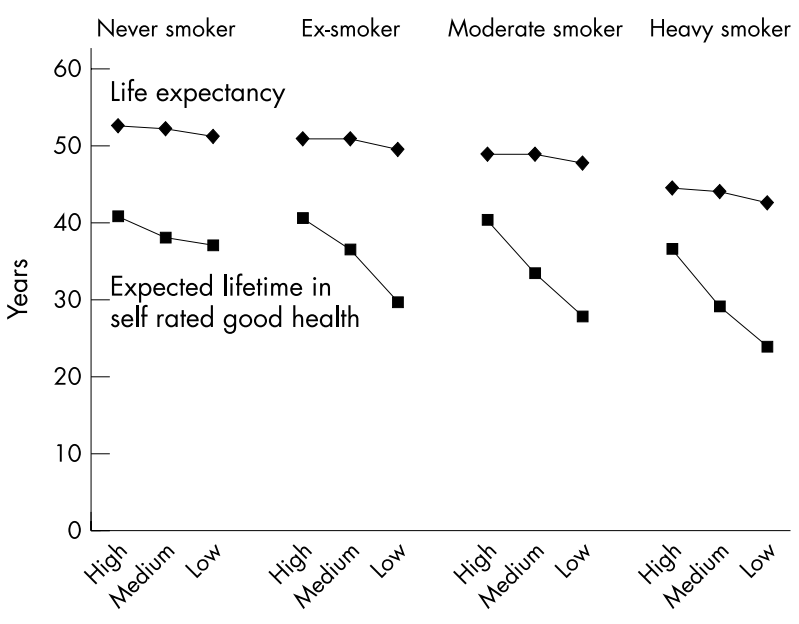

Educational level

Figure 1 Social gradient in life expectancy and expected lifetime in self rated good health in different smoking categories.

Expected lifetime without longstanding illness

Table 2 shows that the expected lifetime without longstanding illness was 28.7 years and 29.4 years for 30 year old never smoking men and women, respectively; this was almost eight years longer than that of lifelong heavy smokers and almost four years longer than that of moderate smokers. Smoking reduces expected lifetime without longstanding illness in all educational groups. The social gradient among lifetime never smokers was less pronounced among women than men, whereas that of heavy smokers was more pronounced for women than men (fig 2).

\section{DISCUSSION}

We found that smoking reduces life expectancy and expected lifetime in a healthy state irrespective of educational level. The life expectancy gap between educational levels is wider among smokers than never smokers, but smoking does not explain the social gradient in health expectancy, although smoking tends to strengthen the social gradient among women.

The construction of life tables was based on population data and mortality data for all inhabitants of Denmark. Data on educational level of Danes younger than 75 were established from national registers by linkage at the individual level by the unique personal identification code. Thus, sex and age specific death rates were calculated exactly for each educational level. But Statistics Denmark has no data about the educational level of people over 75 . This lack did not introduce a serious bias into this study as it is related to the systematic data collection procedure at Statistics Denmark and not a matter of non-response. We assumed that death rates after age 75 were the same for all educational groups implying an underestimate of differences in life expectancy.

The crux of the matter was to estimate deaths caused by smoking in order to construct life tables by smoking category. The special quality of the method of Peto et al is that it does not require information about smoking prevalence, because the estimated "synthetic smoking prevalence" summarises the history of smoking in the population. What are required however, are lung cancer death rates among people who had never smoked. Because lung cancer is very rare among never smokers few studies are big enough to give reliable estimates. However, the size of CPS-II (more than one million adult Americans) permitted estimation of lung cancer death rates among never smokers, but was not big enough to estimate lung cancer death rates among never smokers by educational level and we had to assume equal rates between educational groups. If lung cancer death rates attributable to other risk factors than smoking differ between educational groups, the method of Peto et al might introduce a bias as to the estimated difference in smoking attributable mortality between the groups. Furthermore, relative risks for other smoking related causes of death than lung cancer were assumed to be the same among educational groups. However, smoking category aggregated lung cancer death rates by educational level were calculated exactly, which is why the "synthetic smoking prevalence" may still reflect differences between educational groups as to smoking habits (quantity, duration, age at smoking onset, inhaling, etc). Also other smoking related cause specific death rates were calculated exactly for each educational group implying differences between educational groups as to the effect of smoking.

When deaths caused by smoking have been estimated, death rates and life tables for never smokers, ex-smokers, moderate and heavy smokers were constructed on the basis of relative risks for death estimated from DANCOS.

\section{Key points}

- Life expectancy is much longer for people who do not smoke than for people who smoke. Also health expectancy-that is, the average lifetime in good health - is substantially longer for never smokers than the smokers.

- The social gradient in terms of health expectancy is greater than in terms of life expectancy.

- The social gradient in health expectancy cannot be explained by a reverse social gradient in smoking prevalence.

- The impact of smoking on health is present irrespective of educational level.

- The social gradient in health expectancy is seen irrespective of smoking category and is steepest among female lifelong heavy smokers. 


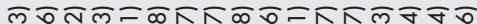

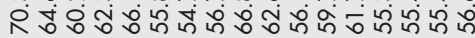

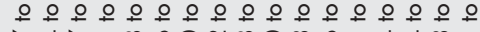
$\Lambda \nabla N-\infty 00 N \infty O m 0-\nabla \nabla m-$

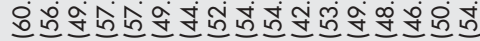

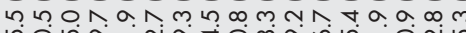

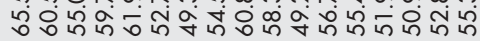

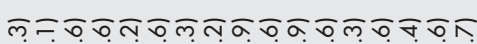

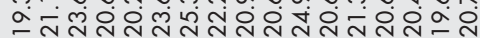

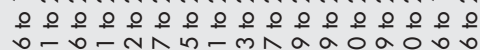

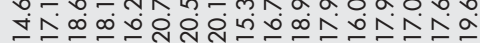
- =

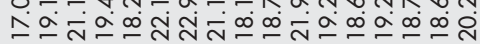

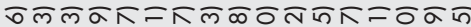

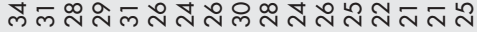
으응ㅇㅇㅇㅇㅇ으으으으으으으오오오오오 amm

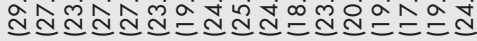
mmon o mm- -

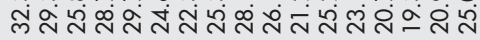

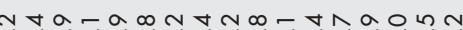

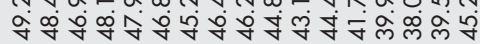

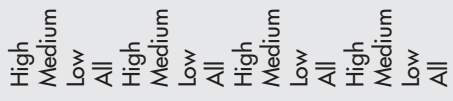

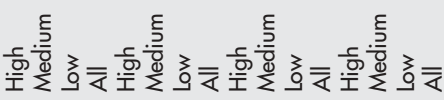

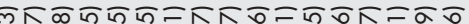

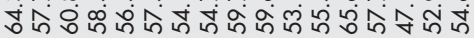

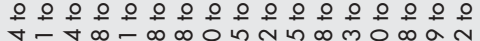

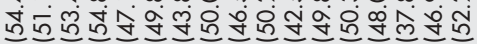
$m \nabla-1 \infty 00 m-a \infty$ o o a $a v$ ถั

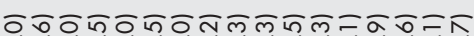

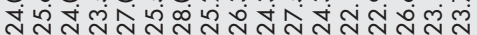
오오오오오으으으으으으으으오으오오 每

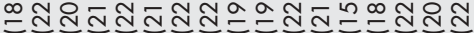

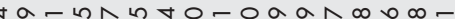

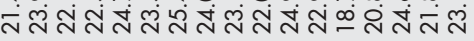

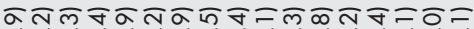
ભำ 온ㅇㅇㅇㅇㅇㅇㅇㅇㅇㅇㅇㅇㅇㅇㅇㅇㅇㅇㅇㅇㅇㅇㅇㅇㅇㅇㅇㅇㅇㅇㅇㅇㅇㅇㅇㅇㅇㅇㅇ ๑ $m+7$
0

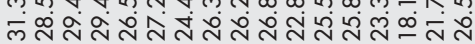

$\nabla \nabla \alpha-\infty \infty m N \infty \infty \nabla 0-\Lambda \backsim 0$

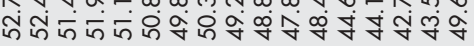

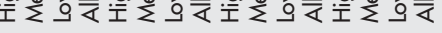
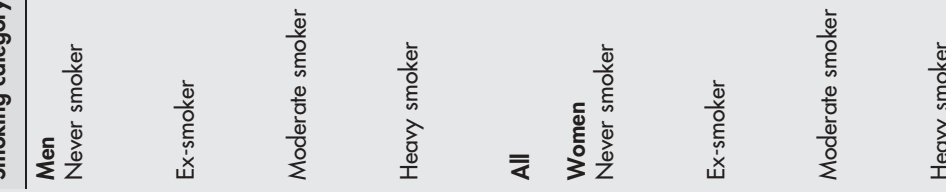


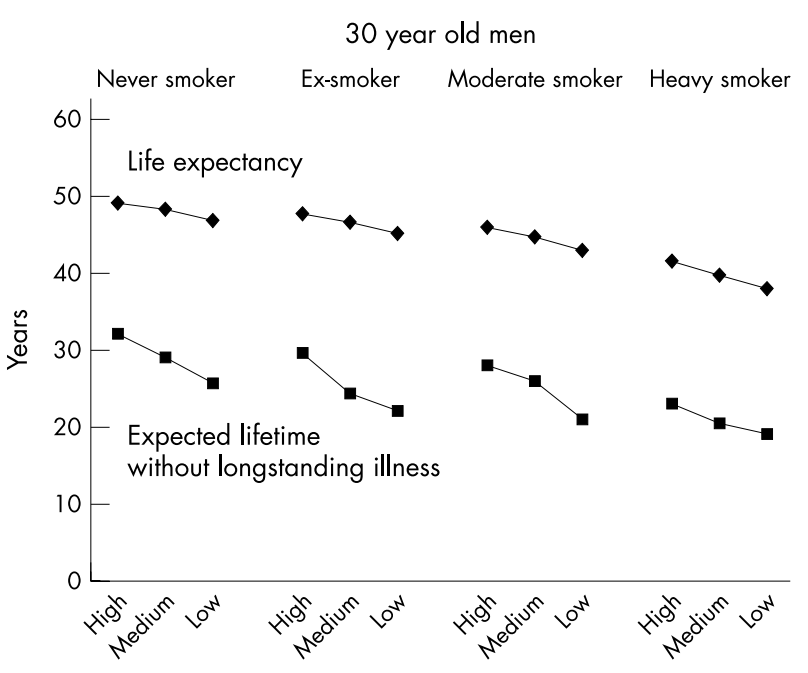

Educational level

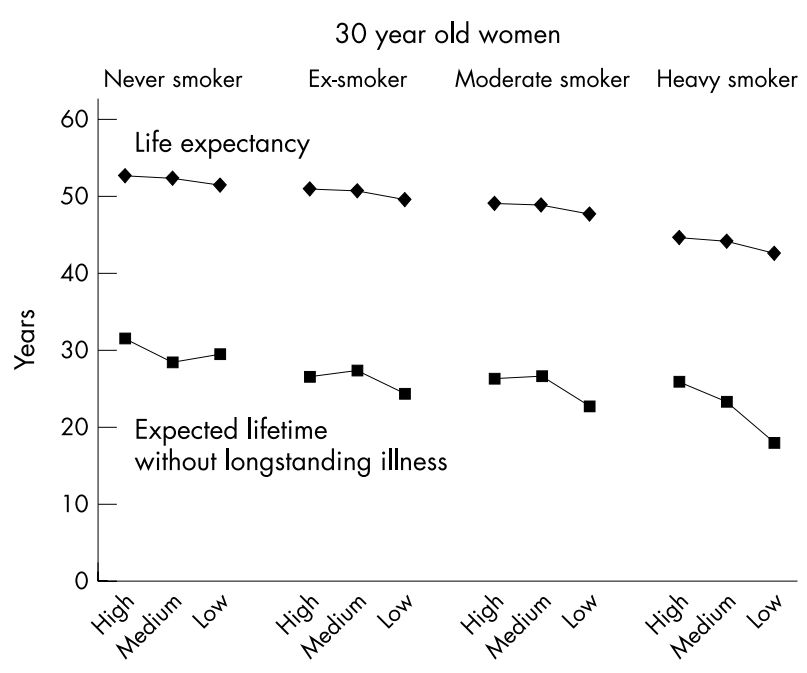

Educational level

Figure 2 Social gradient in life expectancy and expected lifetime without longstanding illness in different smoking categories.

These relative risks were consistent with estimates from other studies including Danish data. ${ }^{9} 10$ But the relative risk estimates were somewhat higher than those estimated in the previous study. ${ }^{1}$ The new estimates were based on more data because of a longer follow up period in DANCOS.

Data on self reported health based on interviews reflect the subjectivity of the interviewees' assessments. This is exactly the point of self rated health. The prevalence of self reported longstanding illness differs considerably from the prevalence based on hospital discharge data, because some diseases seldom lead to hospital admission, whereas other diseases will usually be diagnosed at a hospital. ${ }^{11}$ This must be considered although almost all diseases reported in our study (96\%) were stated to have been diagnosed by a physician.

Self reported data on smoking habits tend to result in underestimated smoking prevalence. ${ }^{12}$ This misclassification could lead to an underestimated difference in health expectancy between smoking categories. Furthermore, the estimated difference between smoking categories is considered to be conservative because the aetiological fractions used to estimate smoking attributable mortality were adjusted downwards to ensure that the hazards of tobacco were not exaggerated. Further details of the validity of the method have been discussed in a previous study. ${ }^{1}$

\section{Authors' affiliations \\ H Brønnum-Hansen, K Juel, National Institute of Public Health, Copenhagen, Denmark \\ Funding: the Danish Ministry of Health grant for research and analysis. Conflicts of interest: none declared.}

\section{APPENDIX}

\section{CONSTRUCTION OF LIFE TABLES BY SMOKING CATEGORY AND EDUCATIONAL LEVEL ON THE BASIS OF THE METHOD OF PETO ET $A L^{5}$}

Let $\mathrm{L}_{\mathrm{i}}$ signify the sex and age specific Danish lung cancer death rate for educational level $\mathrm{i}$ and $\mathrm{A}$ and $\mathrm{C}$ the lung cancer death rates among never smokers and smokers, respectively, according to the second prospective cancer prevention study (CPS-II) of the American Cancer Society on smoking and mortality. A and $\mathrm{C}$ are assumed not to differ between educational levels. Indices for sex and age are suppressed.

If $\mathrm{P}_{\mathrm{i}}$ signify the (sex and age specific) proportion of smokers among persons with educational level $i$, then

$$
\mathrm{L}_{\mathrm{i}}=\mathrm{P}_{\mathrm{i}} \mathrm{C}+\left(1-\mathrm{P}_{\mathrm{i}}\right) \mathrm{A}
$$

The "synthetic smoking prevalence" for the educational level $\mathrm{i}$ is defined as

$$
\mathrm{P}_{\mathrm{i}}=\left(\mathrm{L}_{\mathrm{i}}-\mathrm{A}\right) /(\mathrm{C}-\mathrm{A})
$$

Let RR signify the CPS-II estimate of the relative risk for a smoking related disease other than lung cancer. Then, the aetiological fraction is:

$$
\mathrm{P}_{\mathrm{i}}(\mathrm{RR}-\mathrm{l}) /\left(\mathrm{l}+\mathrm{P}_{\mathrm{i}}(\mathrm{RR}-\mathrm{l})\right)
$$

To ensure that the hazards of tobacco are not exaggerated, the conservative estimate

$$
\mathrm{P}_{\mathrm{i}}(\mathrm{RR}-\mathrm{l}) /\left(2+\mathrm{P}_{\mathrm{i}}(\mathrm{RR}-\mathrm{l})\right)
$$

is used.

This method can be used to estimate educational level, sex, and age specific mortality rates attributable to smoking. Thus, educational level, sex, and age specific death rates, $\mathrm{R}_{\mathrm{i}-\text {, }}$ and a life table for never smokers can be estimated.

These life tables for never smokers and estimates of relative risks for death can be used to calculate death rates for exsmokers $\left(R_{i_{x}}\right)$, moderate smokers $\left(R_{i+}\right)$, and heavy smokers $\left(\mathrm{R}_{\mathrm{i}++}\right)$.

Finally, educational level specific life tables for ex-smokers, moderate smokers, and heavy smokers are constructed using the death rates $R_{i x}, R_{i+}$, and $R_{i++}$

\section{REFERENCES}

1 Brønnum-Hansen $\mathbf{H}$, Juel K. Abstention from smoking extends life and compresses morbidity: A population based study of health expectancy among smokers and never smokers in Denmark. Tobacco Control 2001;10:273-8.

2 Brønnum-Hansen $\mathbf{H}$, Andersen $\mathrm{O}$, Kjøller $\mathrm{M}$, et al. Social gradient in life expectancy and health expectancy in Denmark. Soz Praventiv Med 2004;49:36-41.

3 Kjøller M, Rasmussen NK, eds. Sundhed \& sygelighed i Danmark 2000 og udviklingen siden 1987. [The Danish Health Interview Survey 2000 and the 
development since 1987] [In Danish]. Copenhagen: National Institute of Public Health, 2002

4 Sullivan DF. A single index of mortality and morbidity. Health Services and Mental Health Administration (HSMHA) Health Rep

1971:86:347-54.

5 Peto R, Lopez AD, Boreham J, et al. Mortality from tobacco in developed countries: indirect estimation from national vital statistics. Lancet 1992;339:1268-78.

6 Helweg-Larsen K, Kiøller M, Davidsen M, et al. The Danish National Cohort Study (DANCOS). Registry-based follow-up study of The Danish Health Interview Surveys, 1987, 1991 and 1994. Dan Med Bull 2003:50:177-80.

7 Davidsen M, Kiøller M. The Danish health and morbidity survey-design and analysis. Statistics in Transition 2002;5:927-42.
8 Jagger C, Hauet E, Brouard N. Health expectancy calculation by the Sullivan method: a practical guide. European concerted action on the harmonization of health expectancy calculations in Europe. Paris: EURO-REVES, 2001:29. (REVES paper no 408 .)

9 Prescott E, Osler M, Andersen PK, et al. Mortality in women and men in relation to smoking. Int J Epidemiol 1998;27:27-32.

10 Valkonen T, van Poppel F. The contribution of smoking to sex differences in life expectancy. Four Nordic countries and the Netherlands 1970-1989. Eur J Public Health 1997:7:302-10.

11 Davidsen M, Rasmussen NK. A comparison of longstanding diseases based on survey data and national patient registry of admission. [Abstract]. Annual EUPHA meeting, Brussels, 2001:32.

12 Patrick DL, Cheadle A, Thompson DC, et al. The validity of self-reported smoking: a review and meta-analysis. Am J Public Health 1994;84:1086-93. 